\title{
Performance Analysis of 3G+ Cellular Technologies with Mobile Clients
}

\author{
J.A. Esquerra-Soto* ${ }^{1}$, J.A. Pérez-Díaz ${ }^{2}$, I. Amezcua-Valdovinos ${ }^{3}$, C.F. García-Hernández ${ }^{4}$ \\ 1,2,3 Instituto Tecnológico de Monterrey, Campus Cuernavaca \\ Autopista del Sol, km. 104 \\ Col. Real del Puente, C.P. 62790 \\ Cuernavaca, Morelos, México \\ ${ }^{4}$ Instituto de Investigaciones Eléctricas \\ Reforma 113, Col. Palmira, C.P. 62490 \\ Cuernavaca, Morelos, México \\ juanalonso.es@gmail.com
}

\begin{abstract}
This work presents a performance evaluation of two of the most popular end-to-end third generation technologies. The technologies analyzed were EVDO Rev. A and HSDPA. Although these technologies are present around the world, most of the work based on these technologies is only simulation, being most of the real-case scenario investigations, internal carrier studies. We used a real-case scenario using TCP and UDP. We measured throughput, jitter and packet loss/discard as QoS performance parameters. We performed tests using both technologies concurrently with two identical computers at downlink and uplink at $0 \mathrm{~km} / \mathrm{h}, 60 \mathrm{~km} / \mathrm{h}$ and $90 \mathrm{~km} / \mathrm{h}$. These computers send/receive data to a static server host located in California. In general, we noticed that HSDPA and EVDO lose performance when speed increases. The most affected performance parameter was the throughput being most of the average values under 50 percent of the nominal throughput value. At downlink, HSDPA was the most speed increase sensitive technology and at uplink EVDO was the most speed sensitive. HSDPA at downlink goes from 32.9 percent of the nominal throughput value to 8.57 percent of nominal throughput value at $90 \mathrm{~km} / \mathrm{h}$. EVDO in the uplink goes from 17.11 percent of nominal throughput value to 6.79 percent of the nominal throughput value at $90 \mathrm{~km} / \mathrm{h}$.
\end{abstract}

Keywords: throughput, HSDPA, EVDO, jitter, packet loss, mobile clients.

\section{RESUMEN}

Este trabajo presenta una evaluación de desempeño de dos de las más populares tecnologías de tercera generación. Las tecnologías analizadas fueron EVDO Rev. A y HSDPA. Pese a que ambas tecnologías están presentes alrededor del mundo, la mayoría de trabajos de investigación basados en éstas son simulaciones, siendo estudios internos de las operadoras la mayoría de trabajos con escenarios reales. Medimos rendimiento, jitter y paquetes perdidos/descartados como parámetros usando los protocolos TCP y UDP. Realizamos pruebas utilizando ambas tecnologías de manera concurrente con dos computadoras idénticas en el sentido de subida/bajada a $0 \mathrm{~km} / \mathrm{h}, 60$ $\mathrm{km} / \mathrm{h}$ y $90 \mathrm{~km} / \mathrm{h}$. En general, observamos que HSDPA y EVDO tienen una degradación de desempeño cuando la velocidad incrementa, siendo más afectado el rendimiento, obteniendo en la mayoría de pruebas valores menores al 50 por ciento del valor nominal. En el sentido de bajada, HSDPA fue la tecnología más sensible al incremento de la velocidad, siendo EVDO la más sensible en el sentido contrario. HSDPA en el sentido de bajada pasó de un 32.9 por ciento del valor nominal de rendimiento en reposo a un 8.57 por ciento a $90 \mathrm{~km} / \mathrm{h}$. Por otro lado EVDO en el sentido de subida pasó de un 17.11 por ciento del valor nominal a un 6.79 por ciento a $90 \mathrm{~km} / \mathrm{h}$.

\section{Introduction}

Since their emergence, cellular technologies have been evolving dramatically with the main purpose of meeting the consumer requirements. The use of mobile devices went from only voice service to a multiservice platform (data, voice, among others). The foregoing created new requirements for cellular networks, like quality of service and higher data bandwidths. The previous problems were solved, among other things, due to the implementation of the CDMA technologies. As CDMA evolved, new technologies appeared, like UMTS (Universal mobile Telecommunications System) with Wideband-CDMA and cdma2000 1xRTT. These technologies provided a dramatically increase of the data available bandwidth and number of services [1]. 
The 3GPP (Third Generation Partnership Project) and the 3GPP2 were established since the implementation of third generation technologies. The main purpose of these organizations is to regulate the development and implementation of new cellular technology standards. 3GPP takes over the UMTS technologies and their evolutions (HSDPA, HSUPA, HSPA+ etc.) while 3GPP2 is responsible for all the cdma2000 technologies (1xRTT, 3xRTT, EVDO, EVDV, and UMB).

UMTS uses a pair of $5 \mathrm{MHz}$ channels and can reach $384 \mathrm{Kbps}$ of throughput performance in both directions in UTRAN (Universal Terrestrial Radio Access Network) with micro-cells [2]. HSDPA (High Speed Downlink Packet Access) works over WCDMA and uses a 16QAM modulation scheme with variable error-rate coding. HSDPA is used for data transmission and reception, and can achieve up to $14 \mathrm{Mbps}$ data rates at the downlink. HSDPA is totally compatible with UMTS and their services [3].

Moreover, in the cdma2000 technologies, a 1xRTT evolution called EVDO (Evolution-Data Optimized) with three revisions ( $0, A$ and $B$ ) appeared. This technology can achieve throughputs from 2.45 Mbps to $4.9 \mathrm{Mbps}$ in the downlink. Since the A revision, a lot of improvements to the technology also appeared, like VolP enhancements and more uplink bandwidth. The highest modulation scheme of EVDO is 16QAM as in HSDPA.

To the best of our knowledge, one of the most used transport protocols in the world is TCP (Transmission Control Protocol). This protocol was created for wired networks, were packet loss is caused by network congestion. Therefore, TCP performance may be dramatically reduced in wireless scenarios where packet losses may be caused by environmental issues like the weather, trees, among other factors and not network congestion.

As mentioned above, packet loss in wireless networks could be caused by obstructions like walls, furniture, cars, among others, and different atmospheric aspects like rain and wind. Additionally, in this work the speed of the mobile client proved to be a cause of packet loss.

A brief introduction to HSDPA and EVDO technologies is shown next.

\subsection{EVDO}

Evolution-Data Optimized or Evolution-Data Only is specified in the TIA-856 (Telecommunications Industry Association) standard. EVDO is an evolution of 1xRTT. EVDO should work with the same antennas and frequency bands used in 1xRTT.

EVDO was mainly developed by Qualcomm, with the aim of meeting the requirements of the IMT2000 standard being an end-to-end technology. Two of the main distinctive specifications of EVDO are the following: adaptive modulation and TDM (Time Division Multiplexing).

In EVDO, the air interface state is represented and measured by the SNR (Signal to Noise Ratio) value. With this SNR value, the mobile device can select one of the three modulation schemes: QPSK (Between -12 and 3.7), 8PSK (Between 1.8 and 7.5) and 16QAM (Between 3.8 and 9.7).

Currently, there are three revisions of EVDO. The first (EVDO Rev 0) was designed to provide 2.4 Mbps in the downlink. After the commercial launch of EVDO, the developers started to work on a revision with an improved user experience. All these improvements were implemented in 2006 with revision A (TIA-856-A standard) [4] [5].

The distinctive improvement of EVDO Rev. A is the higher data bandwidth support, $3.1 \mathrm{Mbps}$ in the downlink and $1.8 \mathrm{Mbps}$ in the uplink. Other improvements are a lower connection establishment time and up to 49 calls per sector support, using the EVRC-Wide Band codec. Almost all of these improvements in the uplink came from the use of QPSK and 8PSK modulation schemes.

In the newer EVDO revision (Rev. B), the technology added multicarrier support so the available bandwidth can be duplicated or triplicated. Also in EVDO Rev. B the carriers can have a selective implementation scheme. Finally, EVDO Rev. B includes 64QAM and TCI (Total Interference Cancelation) schemes [3] [4].

\subsection{HSDPA}

HSDPA is an evolution of UMTS. Since 2006 this technology is present in Europe. It is specified in 
the 3GPP Release 5 standard and shares a lot of specs with UMTS (Release 1999), hence it is backwards compatible with UMTS. HSDPA and HSUPA (Release 6) belong to the so-called HSPA (High Speed Packet Access) technologies. HSDPA can be used to provide Internet end-to-end services.

HSDPA can achieve 1.8, 3.6, 7.2 and 14 Mbps of downlink bandwidth (this performance depends on the implementation). This enhancement was reached due to the implementation of features like new modulation schemes (QPSK and 16QAM), adaptive coding schemes and HARQ (Hybrid Automatic Retransmission Query).

It can be said that HSDPA works with a collective channel shared by the users (HS-DSCH). In early implementations, this channel was not supposed to work with real-time data traffic. This logical channel can be maped to a sort of HS-PDSCH and other physical channels to provide the trasmission.

The HSDPA technology changes its modulation scheme, the number of HS-DPSCH channels and the transport block sizes, based on the state of the air interface. In agreement with the main specs of HSDPA, it was not designed to work with speeds higher than $40 \mathrm{~km} / \mathrm{h}$. HSDPA has several QoS (Quality of Service) mechanisms to ensure maximum performance (throughput) of the network to the users. Besides, HSDPA uses scheduling algorithms like Round Robin, fair throughput, Max Carrier/Interference and proportional fair [6] [7] [8].

\section{Related Work}

Nowadays, there is a considerable amount of related work about $3 G$ technologies, including simulations, performance measurement and optimization.

Among the related work based on performance, we find interesting that of Qi Bi and Stan Vitebsky from Lucent Technologies Inc., called Performance Analysis of 3G-1x EVDO High Data Rate System [9]. They evaluated the performance of EVDO Rev. 0 using simulations. The assessment of performance was based on two parameters: the number of users in the cell and the speed of the mobile client.
The average throughput was obtained from a proportional fair algorithm, in this algorithm the distribution of the bandwidth was the same for all users. However, the results of the simulation were based on probability functions and nominal values; thus, maybe this work cannot provide a good emulation of a real implementation scenario because they did not take other parameters embedded in a real environment such as the obstructions and the radio link state.

According to previous work, found in the paper by M. Harteneck, M. Boloorian, S. Georgoulis and R. Tanner, called Throughput measurements of HSDPA $14 \mathrm{Mbit/s}$ terminal [10], the results depend on a simulation. They attempt to evaluate the performance of HSDPA in the downlink, using a 14 Mbps HSDPA version.

In their work, they used a vector-based simulation scheme in which they try to simulate different scenarios, using various noise factors. Therefore, the performance depends directly on the behavior of the HS-DSCH transport channel, with the proper modulation scheme (QPSK or 16QAM). In this work, we can remark that the traffic type and the packet loss (caused by speed or the state of the environment) were not incorporated into the simulation; hence, the results obtained could not lead to a real implementation. Moreover, we can say that the results of a 14 Mbps HSDPA version might differ from the 1.8, 3.6 and $7.2 \mathrm{Mbps}$ version results.

Another work on EVDO Rev. 0 by G.D.G. Jaime, R.M.M. Leão, E. de Souza e Silva and J. Roberto B. de Marca, called The Effect Of Mobility On The User-Level Fairness Of $A 3 g$ Wireless Technology (Ev-Do)[11] tries to evaluate the performance loss of EVDO using mobile and static environments. They used an especial simulator platform called Tangram II.

In the simulation environment, they perform an implementation of the physical and data link layers of EVDO. They specified all the EVDO modulation schemes and they implemented adaptive modulation. However, in the user part, the speed of the mobile client was not taken into account because they only use the distance from the mobile node to the base station. 
Similarly to the first related work presented, the results of this work may differ from real implementation results because they did not implement many loss performance factors which can affect the performance of this type of networks.

\section{Testing Environment}

Because the main goal of this work is to evaluate the performance of $3 \mathrm{G}+$ technologies (EVDO and HSDPA), we use an existing card named IUSABAM for EVDO Rev. A and a card named TELCEL $3 G$ for HSDPA.

The main specs of the IUSABAM card are a Merlin Novatel PC 720, PCMCIA slot, EV-DO (backward compatible with Rev 0 and 1xRTT) CDMA $800 \mathrm{MHz}$ and CDMA $1900 \mathrm{MHz}$ supports, GPS capability, transmits wireless data at theoretical speeds up to
3.1 Mbps on the downlink and up to $1.8 \mathrm{Mbps}$ on the uplink on EV-DO Rev A capable networks. This card works with IUSACELL, the only carrier of CDMA 3G technologies in Mexico [12]. The marketing name of the product is BAM "Mobile Wideband".

The main specs of the TELCEL3G card are the following: ZTE MF626 Telstra, a USB slot, HSDPA/HSUPA/UMTS 850/1900/2100 MHz (backward compatible with GSM/GPRS/EDGE $850 / 900 / 1800 / 1900 \mathrm{MHz}$ ) supports, transmits wireless data at speeds up to $3.6 \mathrm{Mbps}$ on the downlink on HSDPA capable networks. This card works with TELCEL the main carrier of GSMWCDMA technologies in Mexico [13]. The official name of the product is TELCEL 3G. The TELCEL 3G network works with HSDPA at downlink and UMTS at uplink at the $850 \mathrm{MHz}$ frequency band.

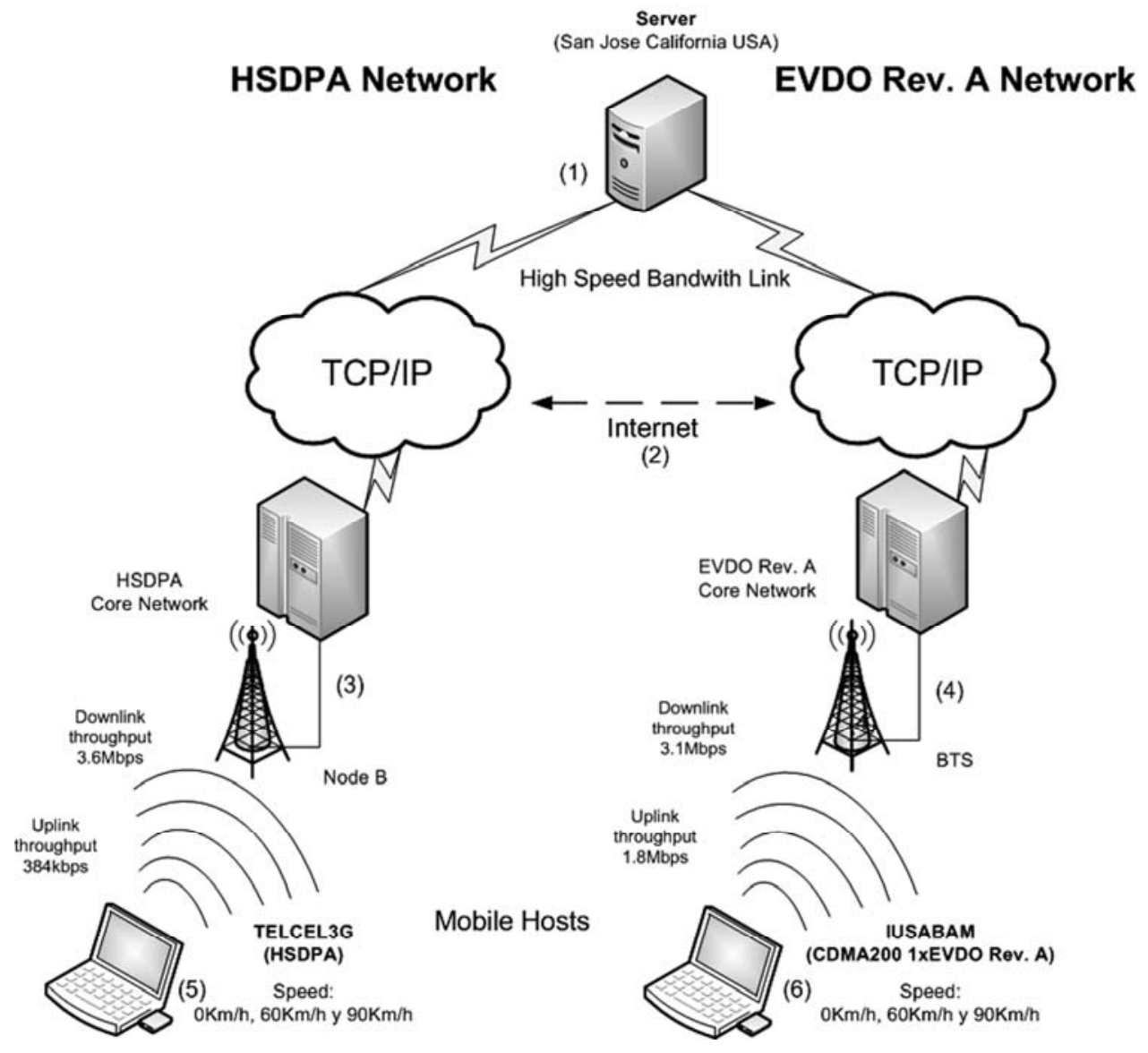

Figure 1. Testing environment architecture. 
As shown in Figure 1, each access card is connected to a mobile computer. These two computers are the mobile hosts of the network. The name of the host depends on the access card connected to the computer. To ensure more accurate results in the technology comparison part, we used two identical laptop computers concurrently.

The main specs of the mobile computers are IBM ThinkPad T43, Processor Intel Pentium M 1.86Ghz, $1.5 \mathrm{~Gb}$ in RAM, $40 \mathrm{~Gb}$ of Hard Disc Drive, PCMCIA and USB ports. The mobile hosts were located at Pachuca City- Sahagun City Highway, km. 4-10, in the state of Hidalgo, Mexico.

Also, we have a static host named SERVER located at San Jose, California. This host has a high-bandwidth internet connection. The main specs of this host are as follows: operating system: Red Hat Linux Advanced Server 4.0, Linux Kernel: 2.6.9-5, Sun Microsystems Java 1.6.0 Update 18, IP Address: 69.22.166.104.

To perform the tests we used shareware-licensed software tools called: Visualware MyConnection Server 9.0g (build 1485) [14] in the SERVER and
Visualware MyConnection PC Business Plus Edition [15] in the mobile computers. These tools generate the needed traffic and control the transfer rates for each test. For the TCP tests we measured the throughput of each mobile client. For the UDP tests we measured the jitter and packet loss. We measured the downlink and uplink values in the access cards (modems).

The information regarding transmission and reception (throughput variation, round trip time, delay, among others), was obtained every second with the help of the software. All the tests were performed with the mobile clients at three different vehicular speeds $(0 \mathrm{~km} / \mathrm{h}, 60 \mathrm{~km} / \mathrm{h}$ and $90 \mathrm{~km} / \mathrm{h})$. Each test was performed within a time period of ten seconds. In order to obtain the best performance in the cellular networks, we performed the tests between 8:30 AM and 01:30 PM.

We performed the same type of tests at each speed $(0 \mathrm{~km} / \mathrm{h}, 60 \mathrm{~km} / \mathrm{h}$ and $90 \mathrm{~km} / \mathrm{h}$ ) using both technologies. Thus, we performed tests for each technology measuring throughput, jitter and packet loss/ discard (240 at rest, 240 at $60 \mathrm{~km} / \mathrm{h}$ and 240 at $90 \mathrm{~km} / \mathrm{h}$ ). The following Figure (Fig. 2) shows the specification and number of tests at each parameter.

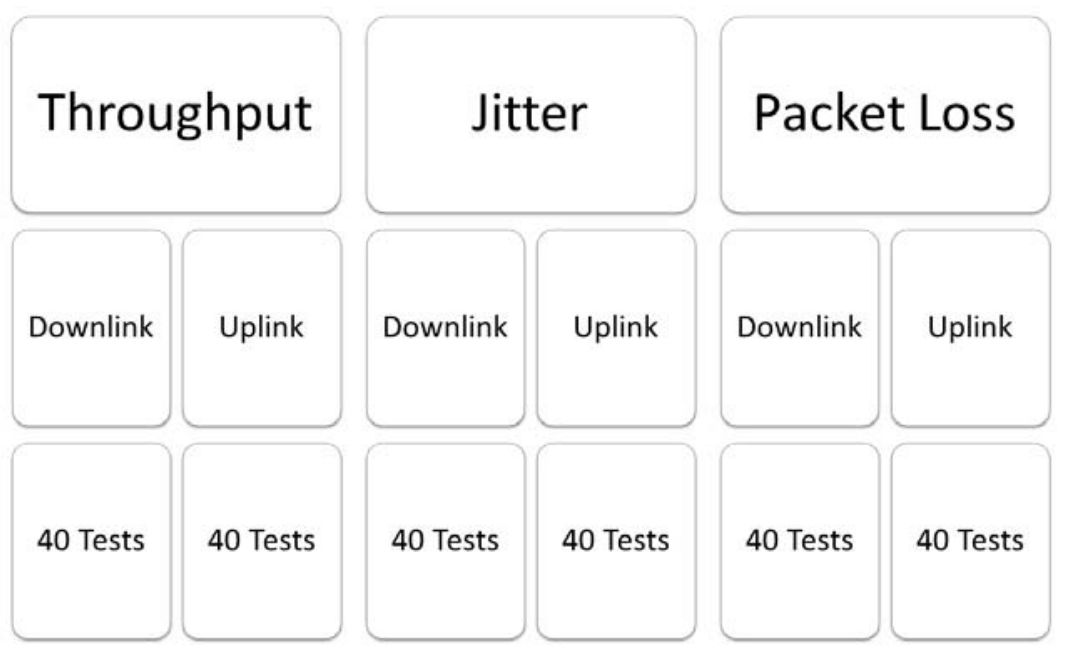

Figure 2. Test parameters at each speed and technology. 
The recommended values for VolP traffic and other real-time applications are less than $20-30 \mathrm{~ms}$ of jitter (carrier grade) and less than 1-2 percent of packet loss/discard. Also with $80-100 \mathrm{~ms}$ of jitter we can have a good enough value for most non real-time applications. Also for VolP the round-trip delay time is an important parameter; therefore, lowest RTT means better performance. The EVDO nominal value of RTT is $250 \mathrm{~ms}$ while the HSDPA nominal value is $150 \mathrm{~ms}$.

\section{Test Results}

In the following graphs we can observe the results of the TCP and UDP tests at different speeds. In the vertical axis we put the average value of the parameter measured and in the horizontal axis we put the number of the test. In the throughput graphs the maximum value of the axis corresponds to the nominal value of the technology.

\subsection{Static Tests}

In Figure 3 we can see our TCP throughput results for the EVDO Rev. A card in the downlink with a mobile host at $0 \mathrm{~km} / \mathrm{h}$ (static). We obtained the average value of $768.8 \mathrm{Kbps}$; this is a 24.8 percent of the nominal value of $3.1 \mathrm{Mbps}$. Additionally, we obtained $1530 \mathrm{Kbps}$ as the highest value and 102 Kbps as the lowest value.

Figure 4 shows our TCP throughput results for the HSDPA card in the downlink with a mobile host at $0 \mathrm{~km} / \mathrm{h}$ (rest). We obtained an average value of $1184.4 \mathrm{Kbps}$; this is a 32.9 percent of the nominal value of $3.6 \mathrm{Mbps}$. Also we obtained $1850 \mathrm{Kbps}$ as the highest value and $146 \mathrm{Kbps}$ as the lowest value.

Thus, if we compare the results of these two technologies, we can detect that in a 70 percent of the tests HSDPA obtained better values than EVDO. In addition to this, the percentage of the nominal value of HSDPA is higher than that of the EVDO value; hence HSDPA outperforms EVDO by an 8.1 percent. With the obtained downlink values, we can say that services like file sharing, HTTP Web access, remote access should perform well with the EVDO and HSDPA networks. Besides, with the throughput values, we could obtain good enough performance to provide multimedia services with the most common codification schemes.

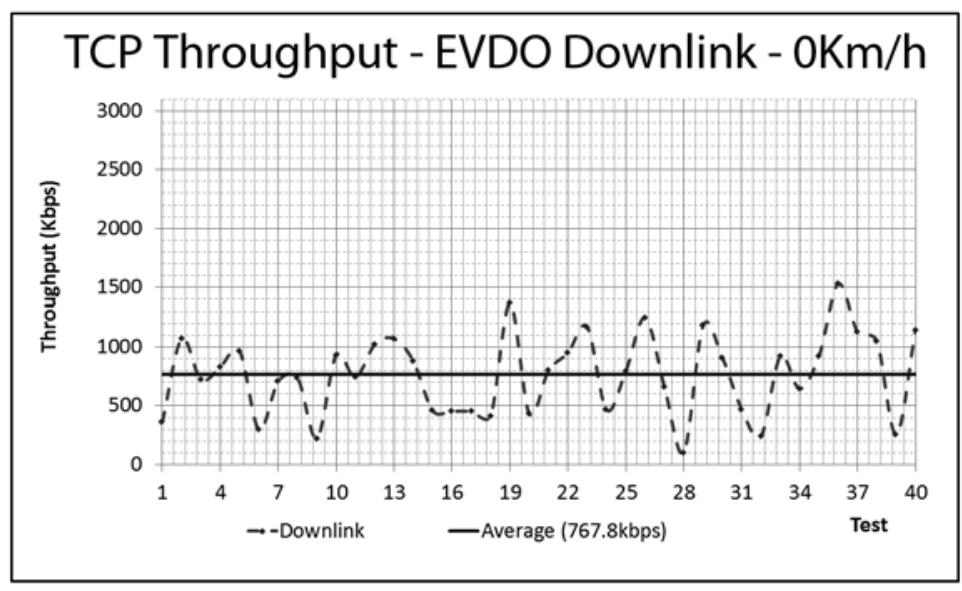

Figure 3. Throughput EVDO downlink static. 


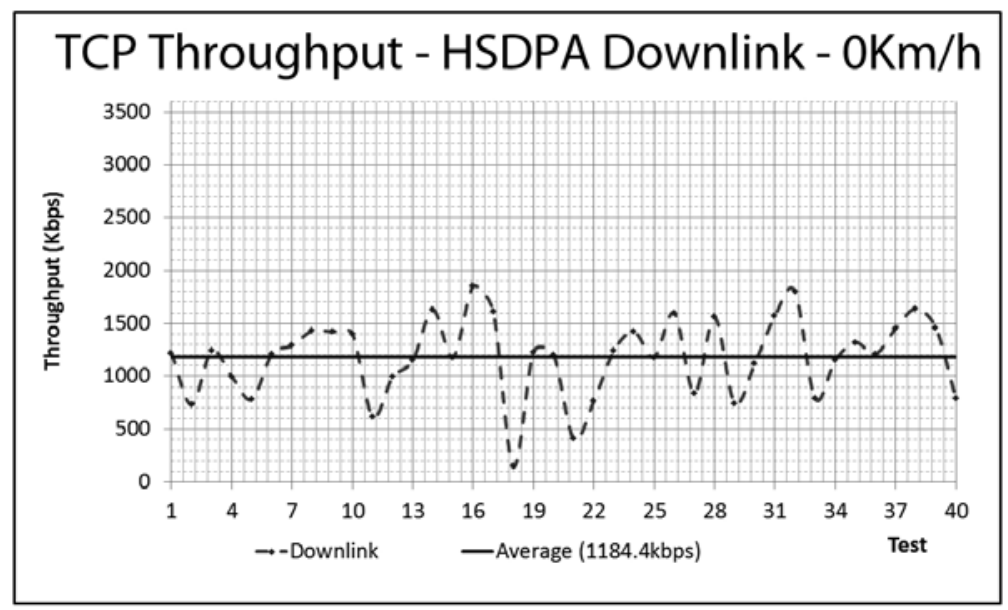

Figure 4. Throughput HSDPA downlink static.

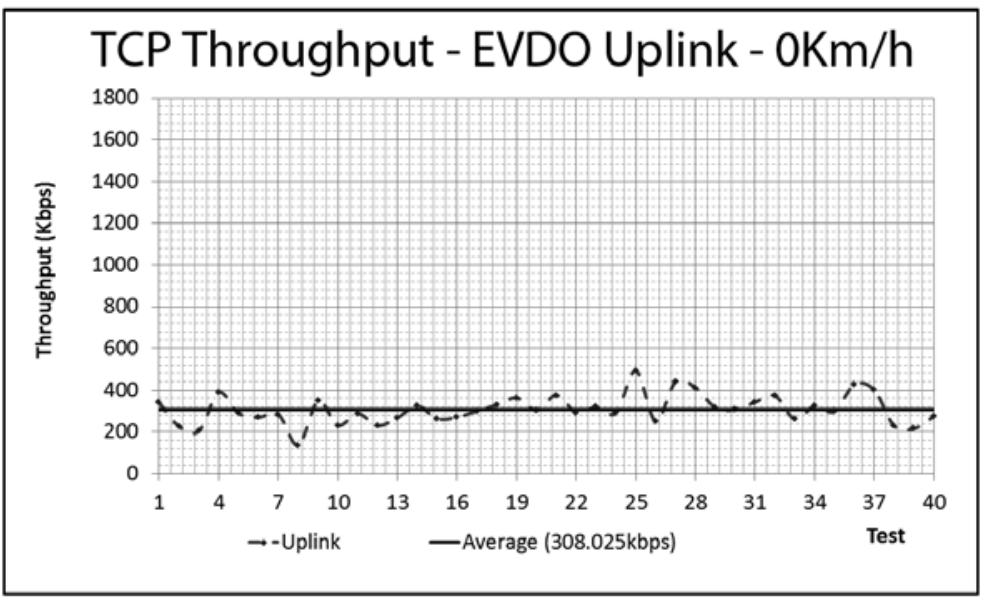

Figure 5. Throughput EVDO uplink static.

Figure 5 shows our uplink TCP throughput results for the EVDO Rev. A at $0 \mathrm{~km} / \mathrm{h}$. We obtained an average value of $308.025 \mathrm{Kbps}$; this is a 17.11 percent of the nominal value of $1.8 \mathrm{Mbps}$. We also obtained $492 \mathrm{Kbps}$ as the highest value and 136 Kbps as the lowest value.

Figure 6 shows our TCP throughput results for the HSDPA card in the uplink with a mobile host at 0 $\mathrm{km} / \mathrm{h}$ (rest). We obtained an average value of $138.0025 \mathrm{Kbps}$; this is 35.94 percent of the nominal value of $384 \mathrm{Kbps}$. Also, we obtained $182 \mathrm{Kbps}$ as the highest value and $68.3 \mathrm{Kbps}$ as the lowest value.
Additionally, if we compare the results of the two technologies in the uplink, we can detect that in all of the tests EVDO obtained better values than HSDPA did. However, the percentage of the nominal value of HSDPA is higher than that of the EVDO value; thus, HSDPA outperforms EVDO by an 18.83percent.

In addition, with the uplink obtained values, we can say that some distributed systems and services could not perform well with the EVDO and HSDPA technologies because the uplink throughput values 
are probably not enough for some types of traffic like videoconferencing.

In the UDP tests we merge the results of the two technologies because there are not any nominal values of jitter and packet loss/discard. Therefore, we can only say if the values obtained are good or bad for a kind of real-time type of traffic.

In the UDP jitter parameter tests (Figure 7), we can see the average values of the two technologies tested. These average values are the following: EVDO obtained $99.7525 \mathrm{~ms}$ and HSDPA obtained
$19.6575 \mathrm{~ms}$. The value of EVDO is higher than that of HSDPA by $80.095 \mathrm{~ms}$. Also, we can detect that the value of EVDO is five times higher than that of the HSDPA value. Besides, the obtained EVDO values have more fluctuation than those of HSDPA.

Figure 8 shows the average values of $69.3825 \mathrm{~ms}$ for EVDO and $143.0875 \mathrm{~ms}$ for HSDPA. However, in this case the best value was obtained by EVDO and the worst value was obtained by HSDPA. Moreover, we can see a peek value of $1041.8 \mathrm{~ms}$ in EVDO and a lot of values of HSDPA are higher than $200 \mathrm{~ms}$.

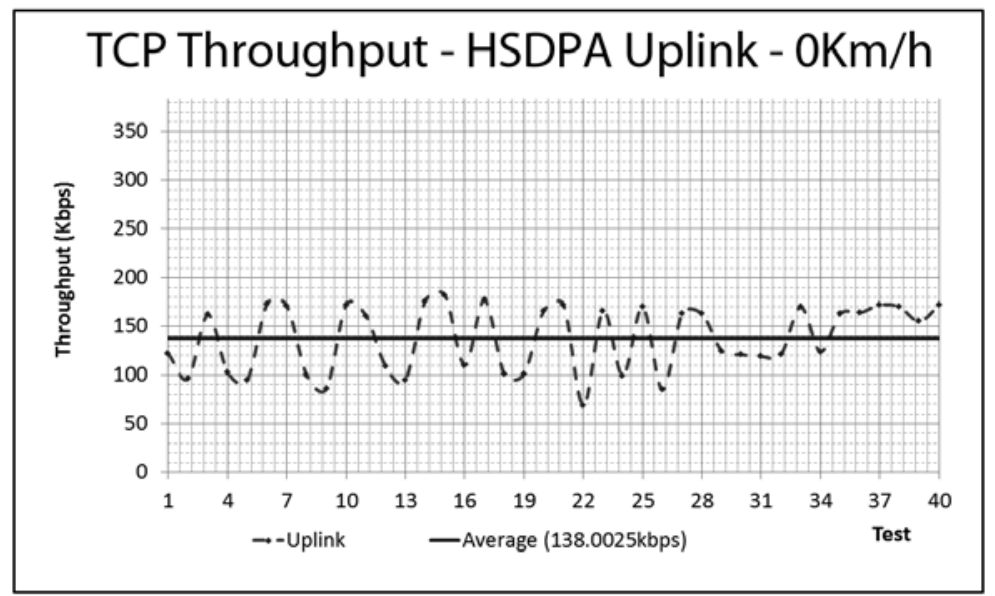

Figure 6. Throughput HSDPA- UMTS uplink static.

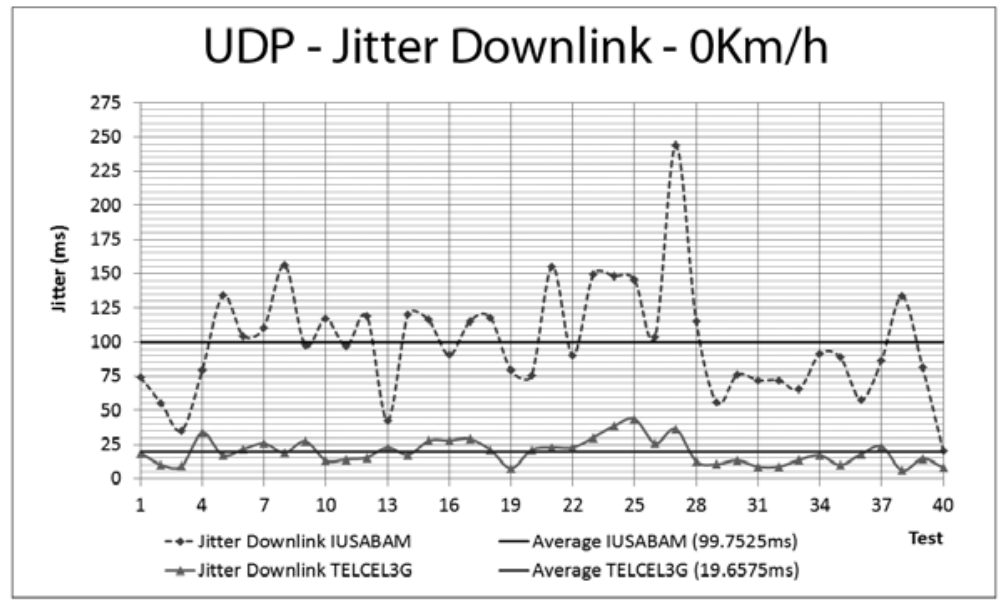

Figure 7. Jitter EVDO and HSDPA downlink 0 km/h. 


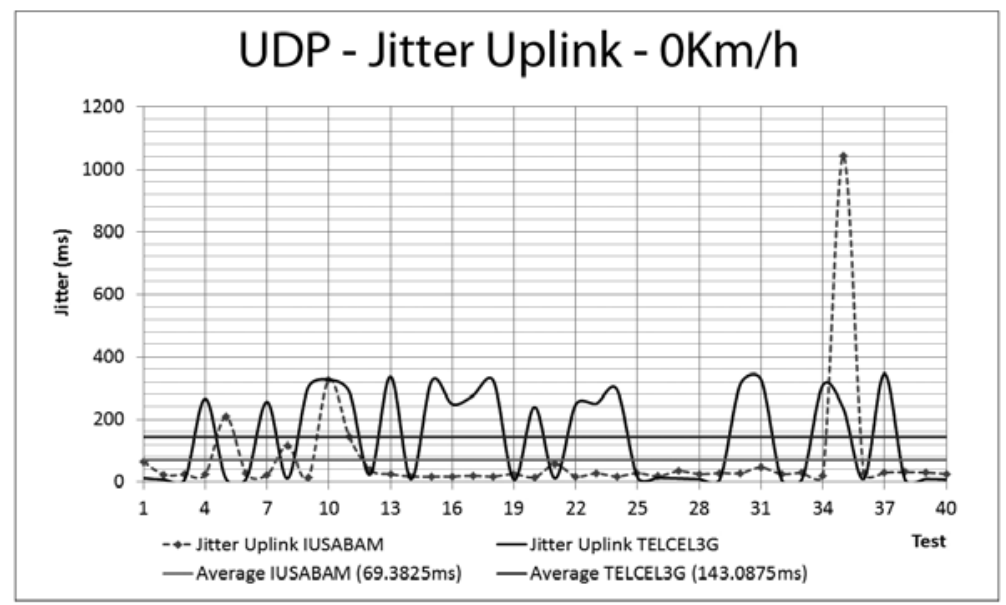

Figure 8. Jitter EVDO and HSDPA uplink $0 \mathrm{~km} / \mathrm{h}$.

We can say that the jitter values of the two technologies are good enough in the downlink because most of them do not exceed the $100 \mathrm{~ms}$ threshold. Nevertheless, at the uplink most of the values are not good for real-time traffic like VolP. In the packet loss tests we take the average percentage of the total sent/received packets.

In the UDP packet loss downlink tests (Figure 9), we can see the following average values: EVDO obtained 0.2425 percent and HSDPA obtained 0.1675 percent. Hence, with the values obtained, we can say that the technologies would perform well because the average packet loss does not reach the 1 percent. However, in one test EVDO exceeds the 1 percent, obtaining 2.8 percent of packet loss.

Additionally, we can observe that the obstructions could affect more the performance of EVDO technologies than HSDPA. An interesting observation appears when we see that in 75 percent of the 40 tests HSDPA does not have any packet loss.

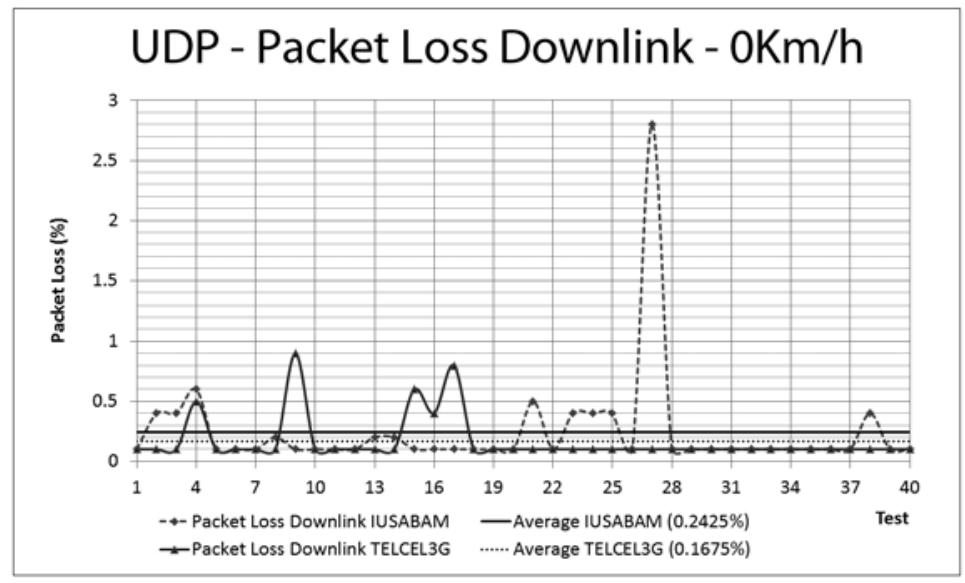

Figure 9. Packet loss EVDO and HSDPA downlink 0 km/h. 
On the other hand, in the uplink, the UDP packet loss (Figure 10) was 0.105 percent in EVDO and 0.045 percent in HSDPA.

In general, we obtained good values because we do not reach the 1 percent of the total packets. We obtained 75 percent of null packet loss; nevertheless, in this case this value belongs to EVDO in the uplink.

\subsection{Mobile Tests: $60 \mathrm{~km} / \mathrm{h}$}

Figure 11 shows our TCP throughput results for the EVDO Rev. A card in the downlink with a mobile host at $60 \mathrm{~km} / \mathrm{h}$. We obtained an average value of $706.645 \mathrm{Kbps}$; this is a 22.8 percent of the nominal value of $3.1 \mathrm{Mbps}$. Also, we obtained 1330 $\mathrm{Kbps}$ as the highest value and $77.8 \mathrm{Kbps}$ as the lowest value.

Figure 12 shows our TCP throughput results for the HSDPA card in the downlink with a mobile host at $60 \mathrm{~km} / \mathrm{h}$. We obtained the average value of $774.3 \mathrm{Kbps}$; this is a 21.5percent of the nominal value of $3.6 \mathrm{Mbps}$. Also we obtained $1300 \mathrm{Kbps}$ as the highest value and $246 \mathrm{Kbps}$ as the lowest value.

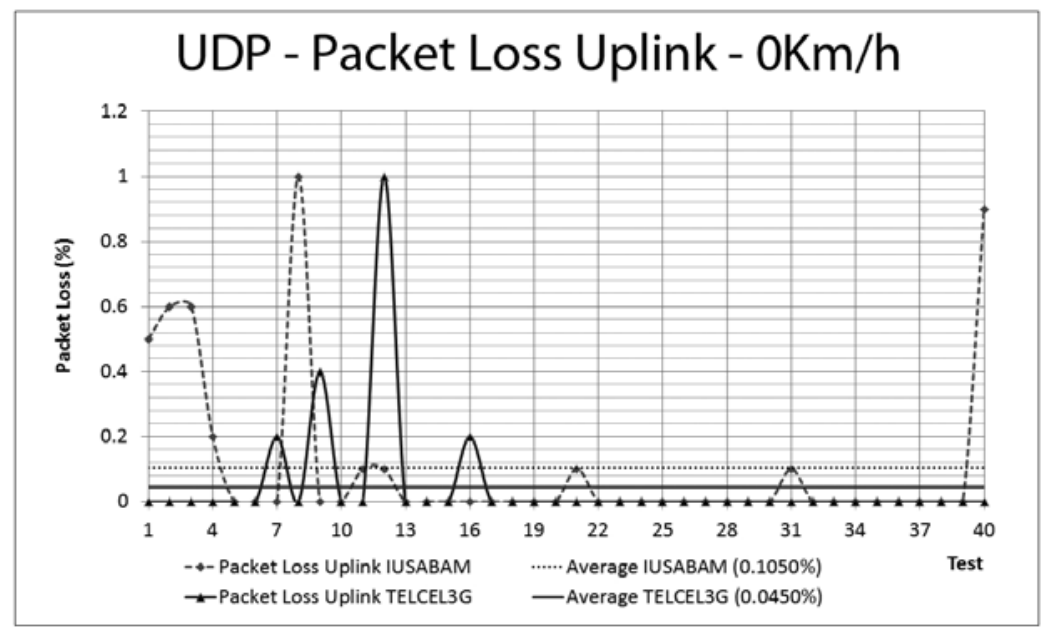

Figure 10. Packet loss EVDO and HSDPA uplink 0 km/h.

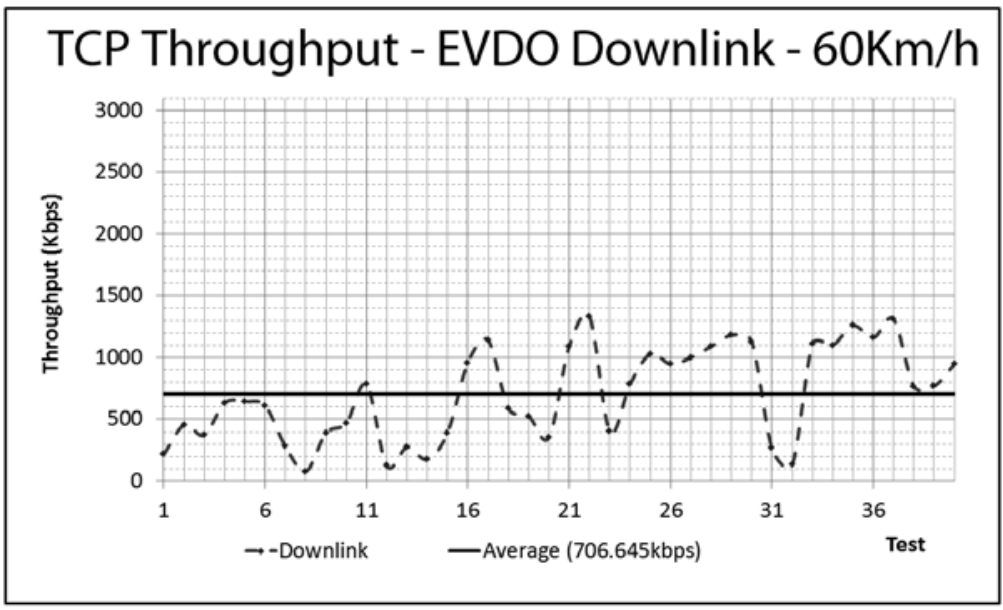

Figure 11. Packet loss EVDO and HSDPA uplink 0 km/h. 


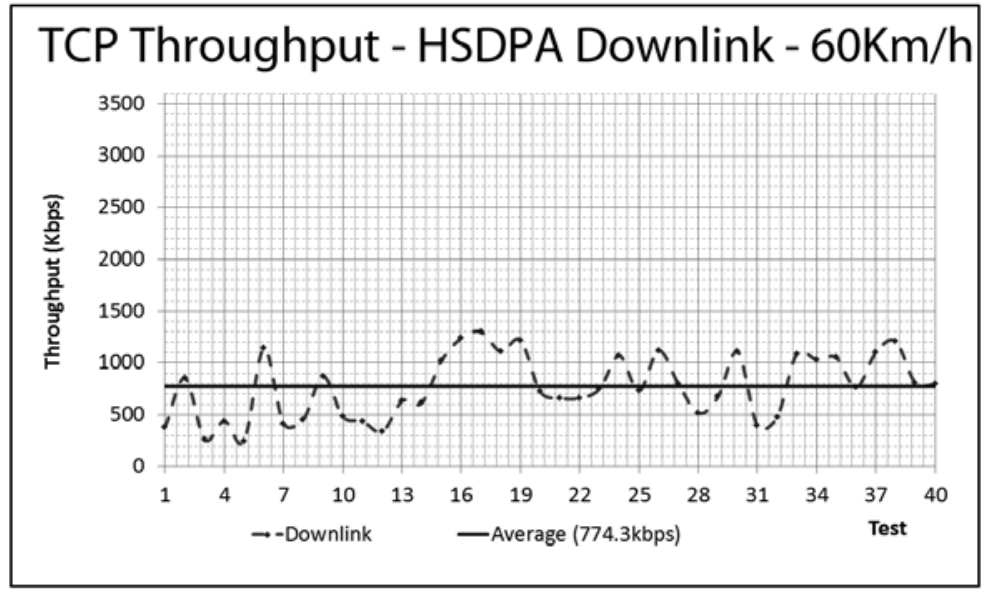

Figure 12. Throughput HSDPA downlink $60 \mathrm{~km} / \mathrm{h}$.

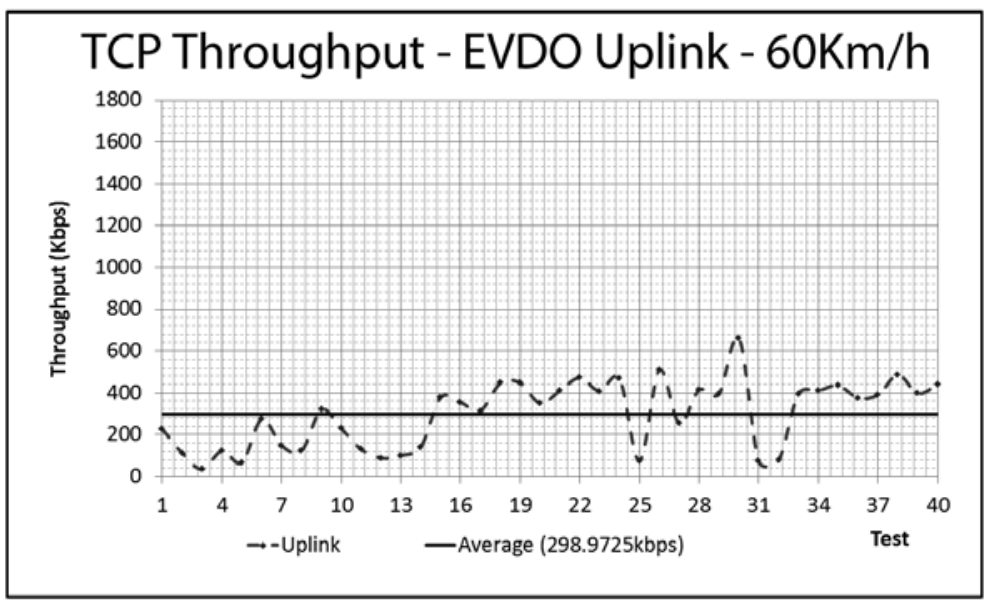

Figure 13. Throughput EVDO uplink $60 \mathrm{~km} / \mathrm{h}$.

Thus, if we compare the results of the two technologies, we can detect that in a 57.5 percent of the tests HSDPA obtained better values than EVDO. In addition, the percentage of the nominal value of HSDPA is higher than that of the EVDO value, hence, HSDPA outperforms EVDO by only 1.3 percent.

Figure 13 shows our TCP throughput results for the EVDO Rev. A card in the uplink with a mobile host at $60 \mathrm{~km} / \mathrm{h}$. We obtained the average value of 298.9725 Kbps; this is a 16.61 percent of the nominal value of $1.8 \mathrm{Mbps}$. Also we obtained $663 \mathrm{Kbps}$ as the highest value and $35.1 \mathrm{Kbps}$ as the lowest value.
Figure 14 shows our TCP throughput results for the HSDPA card in the uplink with a mobile host at $60 \mathrm{~km} / \mathrm{h}$. We obtained the average value of $134.905 \mathrm{Kbps}$; this is a 35.13 percent of the nominal value of $384 \mathrm{Kbps}$. Also, we obtained 194 Kbps as the highest value and $75.6 \mathrm{Kbps}$ as the lowest value. In the same way, if we compare the results of the two technologies, we can detect that in a 72.5 percent of the tests EVDO obtained better values than HSDPA. In addition, the percentage of the nominal value of HSDPA is higher than EVDO: therefore, HSDPA outperforms EVDO by an 18.52 percent. 


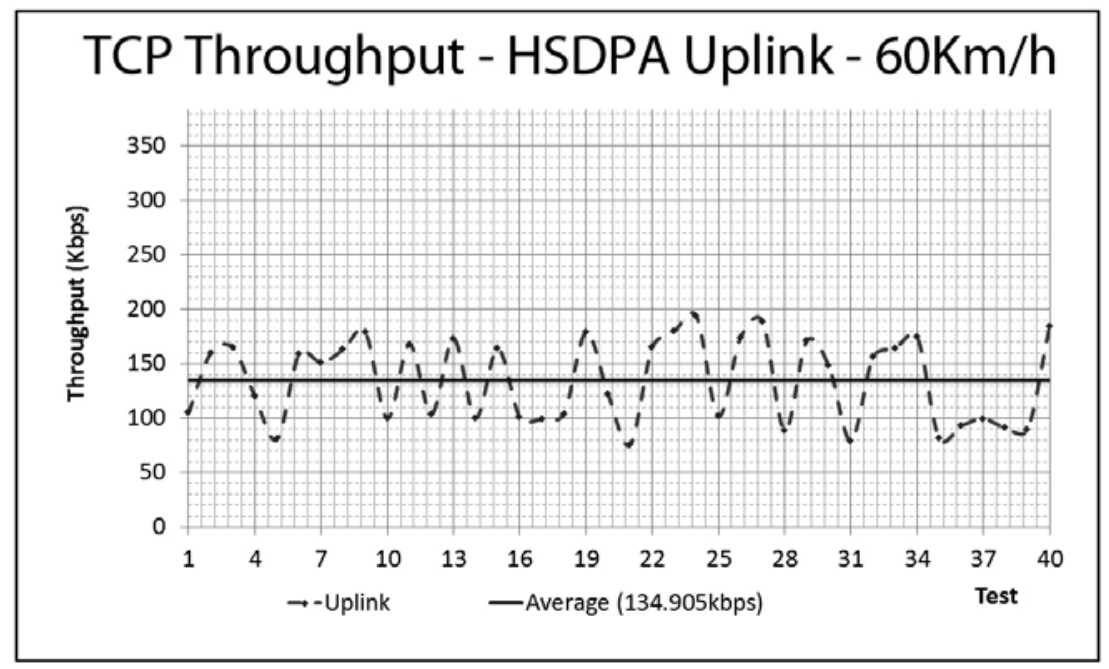

Figure 14. Throughput HSDPA uplink 60 km/h.

Starting again with the UDP tests in the downlink, at $60 \mathrm{~km} / \mathrm{h}$, EVDO (Figure 15) obtained an average jitter value of $107.5425 \mathrm{~ms}$, which is higher than that of the HSDPA value of 33.7975 ms. Thus, with the obtained values we can say that the two technologies support almost the same services than the rest.
If we observe the uplink results (Figure 16), we can see a little increase of the average values from a static environment to a mobile one. The average values of jitter at the uplink with a mobile client at $60 \mathrm{~km} / \mathrm{h}$ are $206.0525 \mathrm{~ms}$ in EVDO and 10.6725 $\mathrm{ms}$ in HSDPA. Hence, with the obtained jitter values VoIP traffic will not perform well.

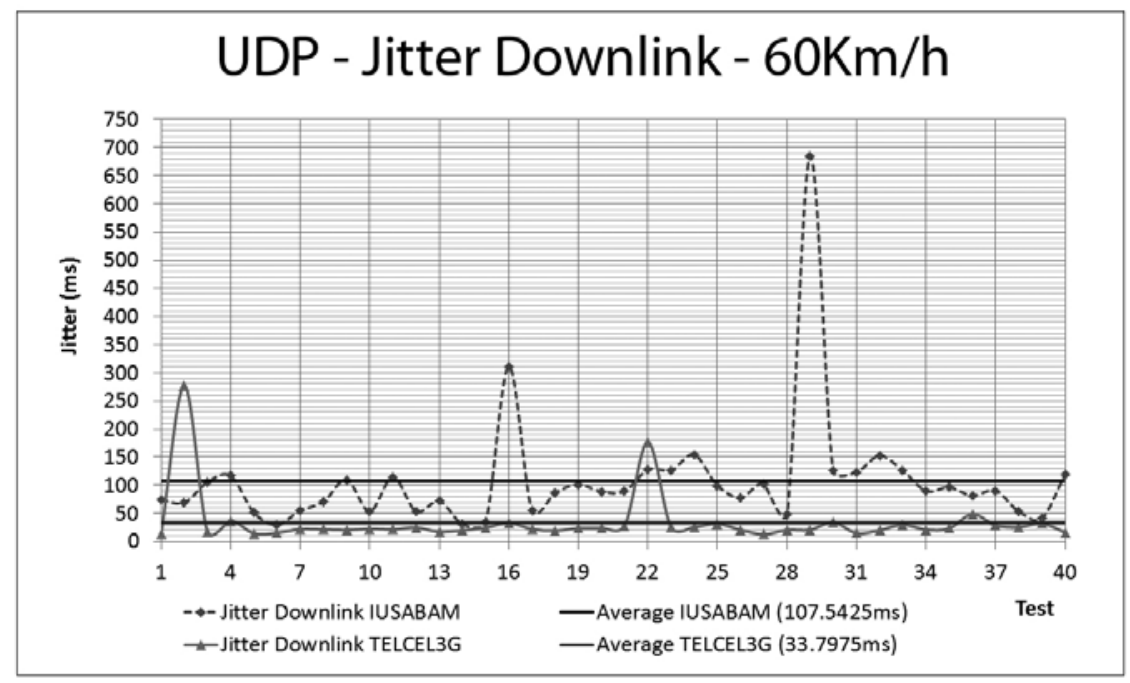

Figure 15. Jitter EVDO and HSDPA downlink $60 \mathrm{~km} / \mathrm{h}$. 


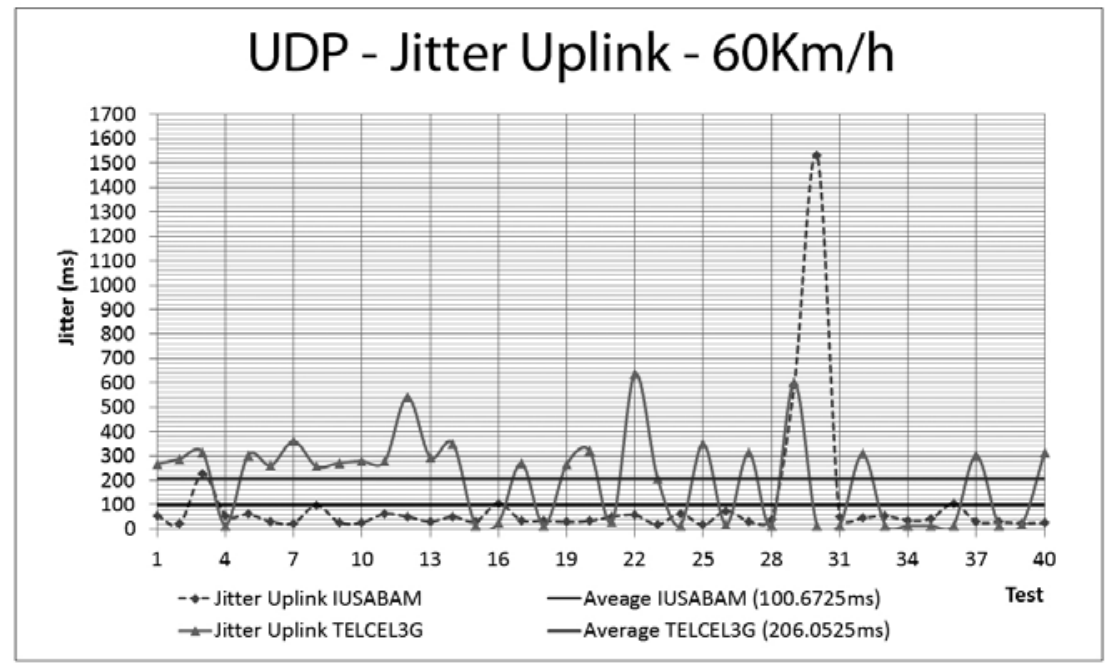

Figure 16. Jitter EVDO and HSDPA uplink $60 \mathrm{~km} / \mathrm{h}$.

In the UDP packet loss downlink tests (Figure 17) with a $60 \mathrm{~km} / \mathrm{h}$ mobile client, we can see a little higher average value: EVDO obtained 0.745 percent and HSDPA obtained 0.1825 percent. Also we can advise that, in two tests, EVDO obtains 13.6 percent and 9.2 percent, these values are higher than a recommended 1 percent.

On the other hand, in the uplink at $60 \mathrm{~km} / \mathrm{h}$, the UDP average packet loss (Figure 18) was 0.17 percent in EVDO and 0.09 percent in HSDPA. In general, we had again very good values, because we did not reach the recommended 1 percent in the total analyzed packets.

\subsection{Mobile Tests: $90 \mathrm{~km} / \mathrm{h}$}

Figure 19 shows our TCP throughput results for the EVDO Rev. A card in the downlink with a mobile host at $90 \mathrm{~km} / \mathrm{h}$. We obtained the average value of $87.3075 \mathrm{Kbps}$; this is only a 9.27 percent of the nominal value of 3.1 Mbps. Also, we obtained $600 \mathrm{Kbps}$ as the highest value and 55.5 Kbps as the lowest value.

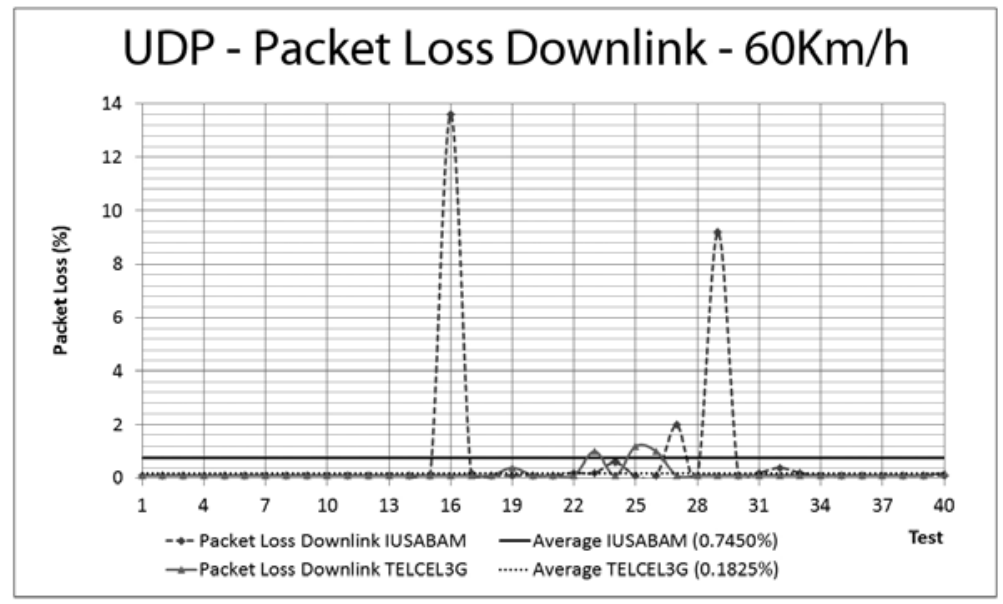

Figure 17. Packet loss EVDO and HSDPA downlink 60 km/h. 


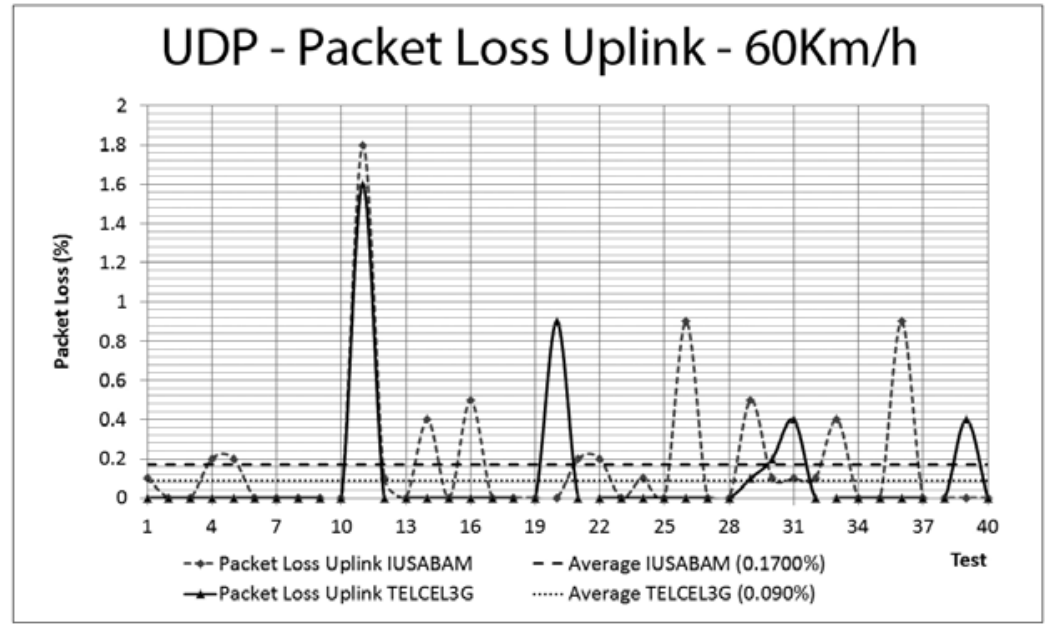

Figure 18. Packet loss EVDO and HSDPA uplink 60 km/h.

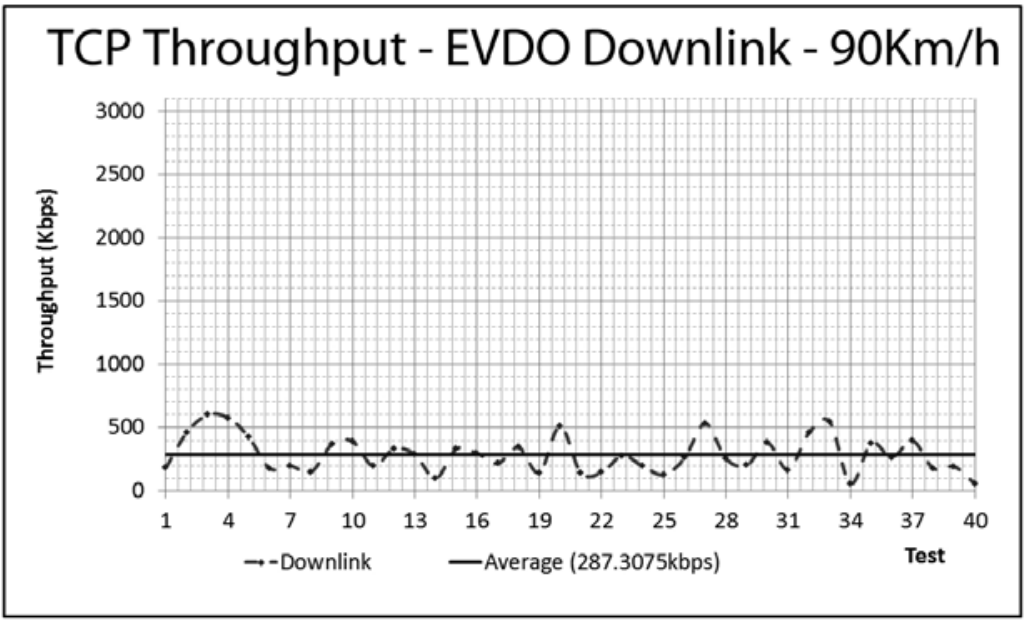

Figure 19. Throughput EVDO downlink 90 km/h.

Figure 20 shows our TCP throughput results for the HSDPA card in the downlink with a mobile host at $90 \mathrm{~km} / \mathrm{h}$ obtained the average value of 308.485 $\mathrm{Kbps}$; this is only 8.57 percent of the nominal value of $3.6 \mathrm{Mbps}$. Also, we obtained $959 \mathrm{Kbps}$ as the highest value and $79.9 \mathrm{Kbps}$ as the lowest value.

If we compare the results of the two technologies, we can detect that in a 57.5 percent of the tests EVDO obtained better values than HSDPA.
Additionally, the percentage of the nominal value of HSDPA is higher than that of EVDO; therefore, HSDPA outperforms EVDO by only 0.7 percent.

Figure 21 shows our TCP throughput results for the EVDO Rev. A card in the uplink with a mobile host at $90 \mathrm{~km} / \mathrm{h}$. We obtained the average value of $122.3125 \mathrm{Kbps}$; this is only a 6.79 percent of the nominal value of $1.8 \mathrm{Mbps}$. Besides, we obtained $297 \mathrm{Kbps}$ as the highest value and $36.4 \mathrm{Kbps}$ as the lowest value. 


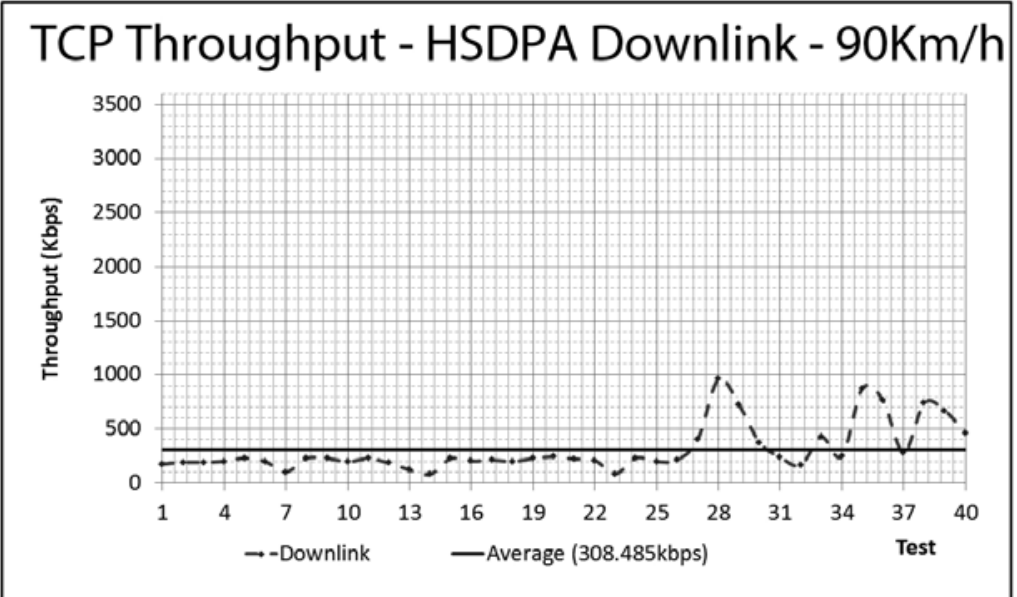

Figure 20. Throughput HSDPA downlink $90 \mathrm{~km} / \mathrm{h}$.

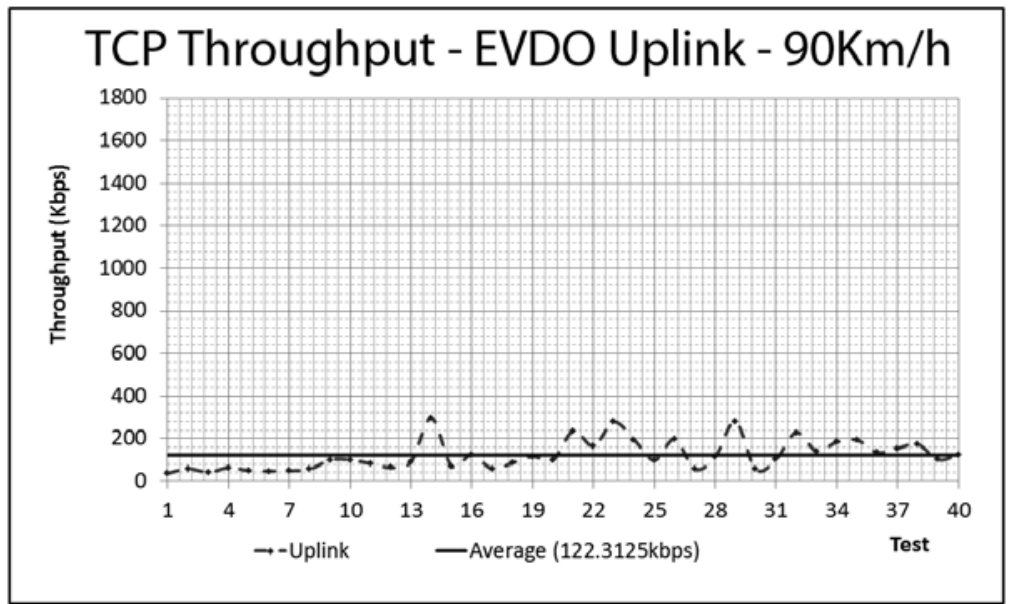

Figure 21. Throughput EVDO uplink $90 \mathrm{~km} / \mathrm{h}$.

Figure 22 shows our TCP throughput results for the HSDPA card in the uplink with a mobile host at $90 \mathrm{~km} / \mathrm{h}$. We obtained the average value of $110.255 \mathrm{Kbps}$; this is a 28.71 percent of the nominal value of $384 \mathrm{Kbps}$. Moreover, we obtained $175 \mathrm{Kbps}$ as the highest value and 36.4 $\mathrm{Kbps}$ as the lowest value.
In the same way, if we compare the results of the two technologies, we can detect that in a 55 percent of the tests HSDPA obtained better results than EVDO. In addition the percentage of the nominal value of HSDPA is higher than that of the EVDO value; thereforem HSDPA outperforms EVDO by 21.92 percent. 


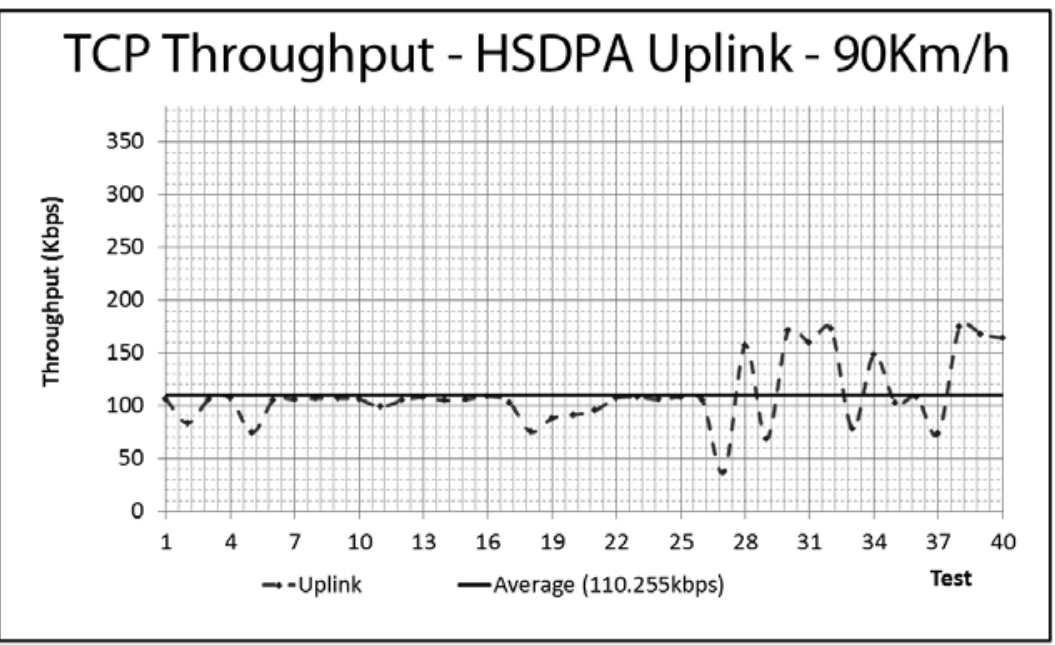

Figure 22. Throughput HSDPA uplink 90 km/h.

When we used a high-speed environment (90 $\mathrm{km} / \mathrm{h}$ ), the average throughput values in the downlink decreased dramatically, being slightly higher than the past technologies' generation nominal values.

In the UDP tests at $90 \mathrm{~km} / \mathrm{h}$, we can see again an increase of the average downlink values of jitter with the two technologies (Figure 23). The average value for EVDO reaches $113.5425 \mathrm{~ms}$, which is higher than the HSDPA value of $48.135 \mathrm{~ms}$.

In the $90 \mathrm{~km} / \mathrm{h}$ tests at uplink (Figure 24) HSDPA obtained $269.38 \mathrm{~ms}$ of average jitter and EVDO $148.95 \mathrm{~ms}$ of average jitter. The average uplink value of HSDPA (UMTS) at this speed $(60 \mathrm{~km} / \mathrm{h})$ remains higher than the EVDO uplink value.

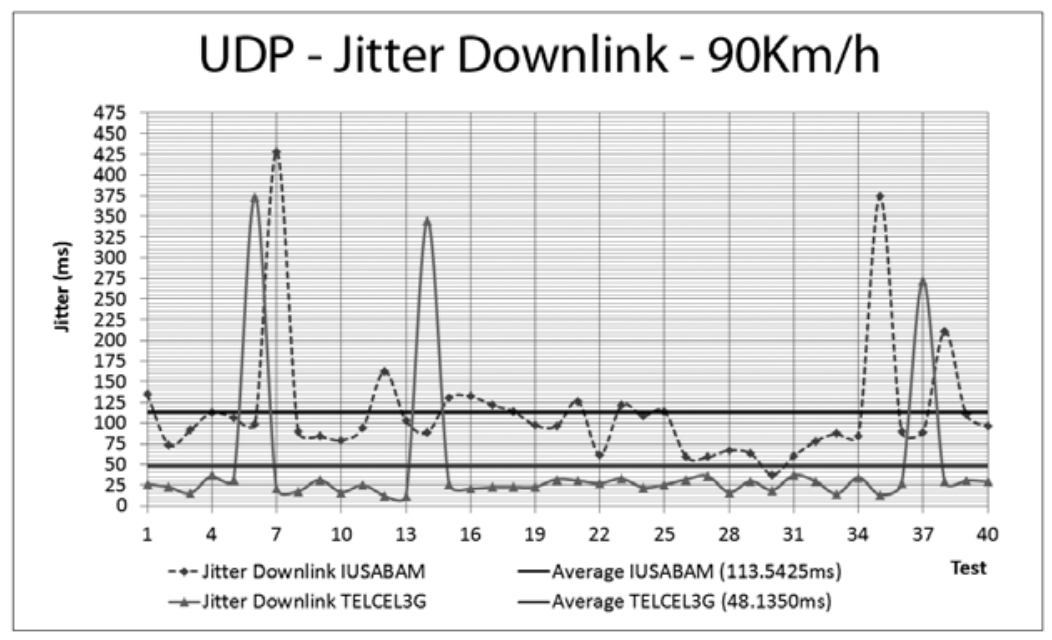

Figure 23. Jitter EVDO and HSDPA downlink $90 \mathrm{~km} / \mathrm{h}$. 
Continuing with the UDP test, at $90 \mathrm{~km} / \mathrm{h}$ (Figure 25), EVDO obtained 2.765 percent and HSDPA 1.2625 percent of downlink packet loss. These values are not good because they are higher than 1 percent. Thus, at this speed, the HSDPA and EVDO technologies are not good for most of applications, especially for real-time applications, because at this speed they are not reliable enough.
Alternatively, in the uplink, the UDP average packet loss (Figure 26) was 0.22percent for EVDO and 0.565 percent for HSDPA. In general, these values are good, but at this speed we have fewer tests with null-packet loss, having 47.5percent in EVDO and 82.5percent in HSDPA.

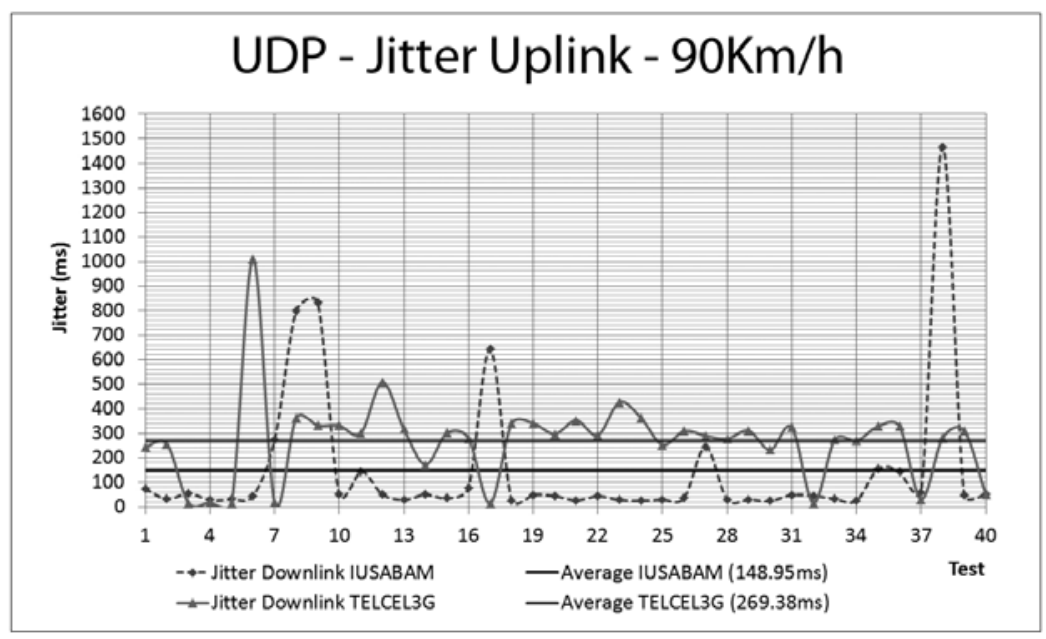

Figure 24. Jitter EVDO and HSDPA uplink $90 \mathrm{~km} / \mathrm{h}$.

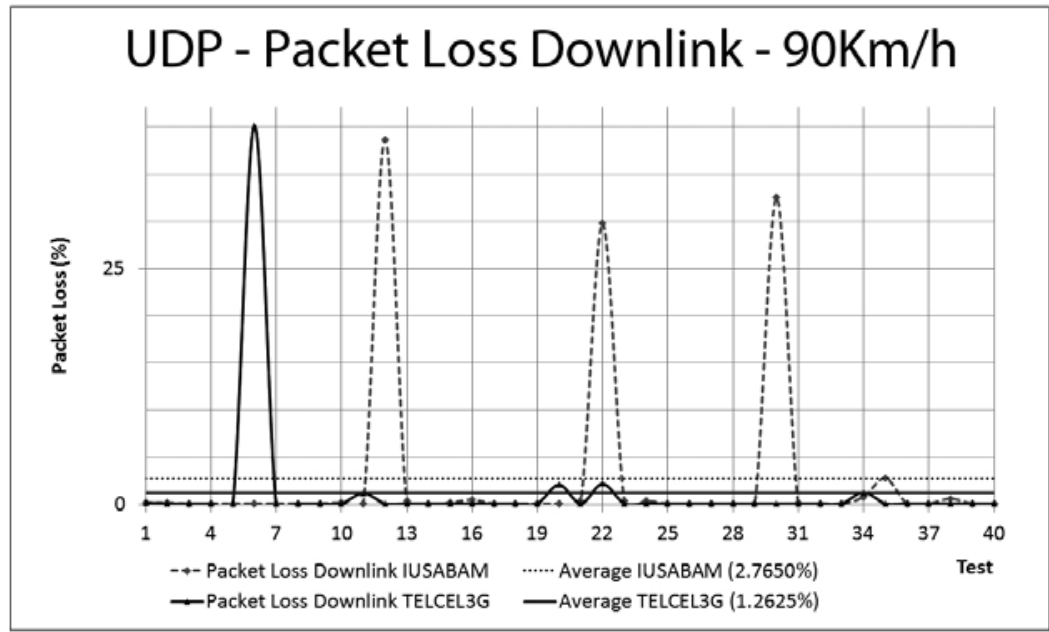

Figure 25. Packet loss EVDO and HSDPA downlink $90 \mathrm{~km} / \mathrm{h}$. 


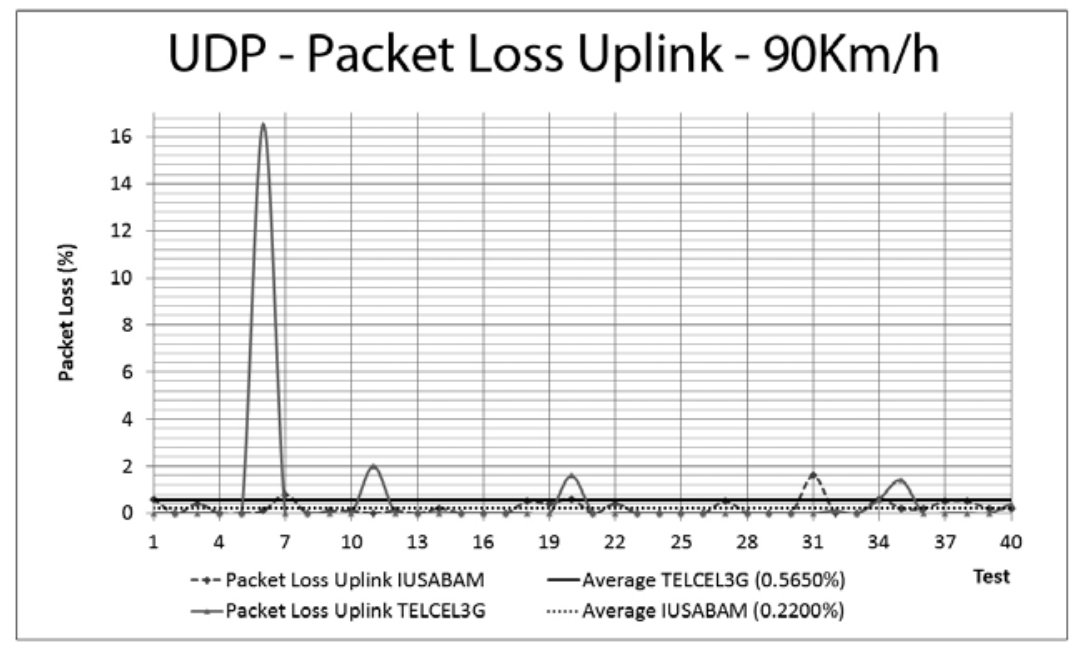

Figure 26. Packet loss EVDO and HSDPA uplink 90 km/h.

\subsection{Mobile Tests Comparisons}

In the throughput TCP tests, HSDPA (Figure 27) obtained a downlink performance loss of 34.63 percent from being at rest to $60 \mathrm{~km} / \mathrm{h}$ speed and 60.16 percent going from $60 \mathrm{~km} / \mathrm{h}$ to $90 \mathrm{~km} / \mathrm{h}$. Also, the uplink performance loss was 22.77 percent from rest to $60 \mathrm{~km} / \mathrm{h}$ speed and 18.7 percent going from $60 \mathrm{~km} / \mathrm{h}$ to $90 \mathrm{~km} / \mathrm{h}$.
On the other hand, in the TCP tests, EVDO obtained a downlink performance loss of 7.96 percent from rest to $60 \mathrm{~km} / \mathrm{h}$ and 59.34 percent going from $60 \mathrm{~km} / \mathrm{h}$ to $90 \mathrm{~km} / \mathrm{h}$. Additionally, the uplink performance loss was 2.94 percent from rest to $60 \mathrm{~km} / \mathrm{h}$ speed and 59.09 percent going from $60 \mathrm{~km} / \mathrm{h}$ to $90 \mathrm{~km} / \mathrm{h}$.

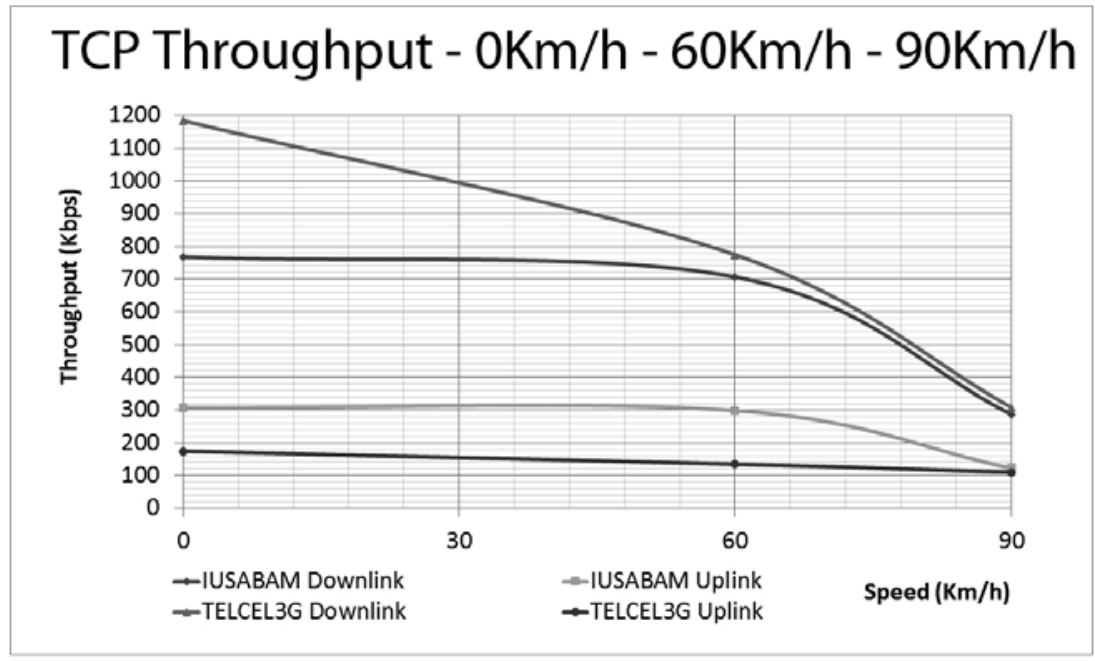

Figure 27. Average throughput EVDO and HSDPA. 
In the jitter UDP tests, HSDPA (Figure 28) obtained a downlink jitter increase of 71.93 percent from rest to $60 \mathrm{~km} / \mathrm{h}$ and 42.42 percent going from $60 \mathrm{~km} / \mathrm{h}$ to $90 \mathrm{~km} / \mathrm{h}$. Besides, the uplink jitter increase was 44.01 percent from rest to $60 \mathrm{~km} / \mathrm{h}$ and 30.73 percent going from $60 \mathrm{~km} / \mathrm{h}$ to $90 \mathrm{~km} / \mathrm{h}$.

However, in the TCP tests, EVDO obtained a downlink jitter increase of 7.81percent from rest to $60 \mathrm{~km} / \mathrm{h}$ speed and 5.58 percent going from 60 $\mathrm{km} / \mathrm{h}$ to $90 \mathrm{~km} / \mathrm{h}$. Thus, the uplink jitter increase was 45.10 percent from rest to $60 \mathrm{~km} / \mathrm{h}$ and 47.96 percent going from $60 \mathrm{~km} / \mathrm{h}$ to $90 \mathrm{~km} / \mathrm{h}$.
With the packet loss parameter UDP tests, HSDPA (Figure 29) only obtained a downlink increase of 0.02 percent from rest to $60 \mathrm{~km} / \mathrm{h}$ and 1.08 percent going from $60 \mathrm{~km} / \mathrm{h}$ to $90 \mathrm{~km} / \mathrm{h}$. Also, in the uplink the packet loss increase was 0.05 percent from rest to $60 \mathrm{~km} / \mathrm{h}$ and 0.48 percent going from $60 \mathrm{~km} / \mathrm{h}$ to $90 \mathrm{~km} / \mathrm{h}$.

On the other hand, in the TCP tests, EVDO obtained a downlink jitter increase of 0.50 percent from rest to $60 \mathrm{~km} / \mathrm{h}$ and 2.02 percent going from 60 $\mathrm{km} / \mathrm{h}$ to $90 \mathrm{~km} / \mathrm{h}$. In the uplink the packet loss increase was only 0.07 percent from rest to $60 \mathrm{~km} / \mathrm{h}$ and 0.05 percent going from $60 \mathrm{~km} / \mathrm{h}$ to $90 \mathrm{~km} / \mathrm{h}$.

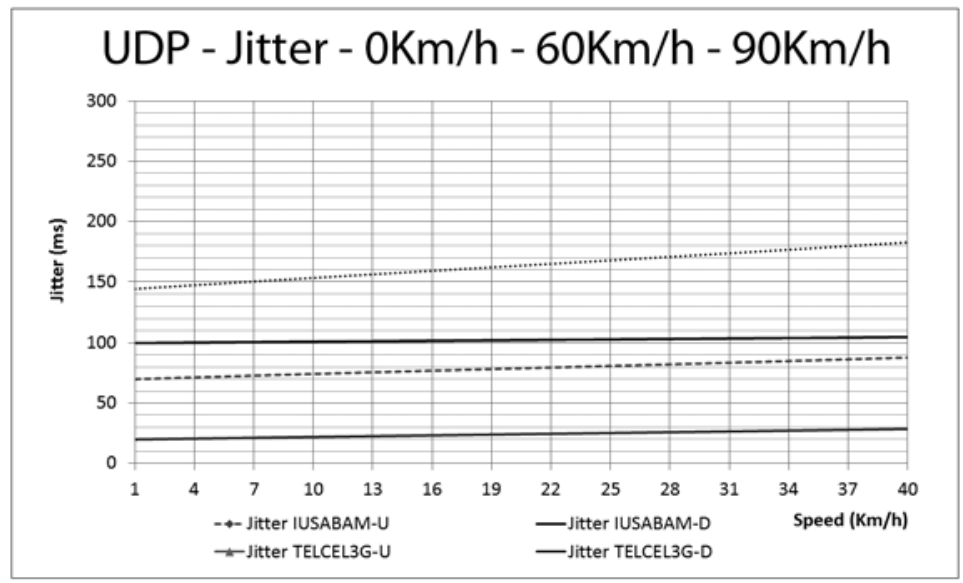

Figure 28. Average jitter EVDO and HSDPA.

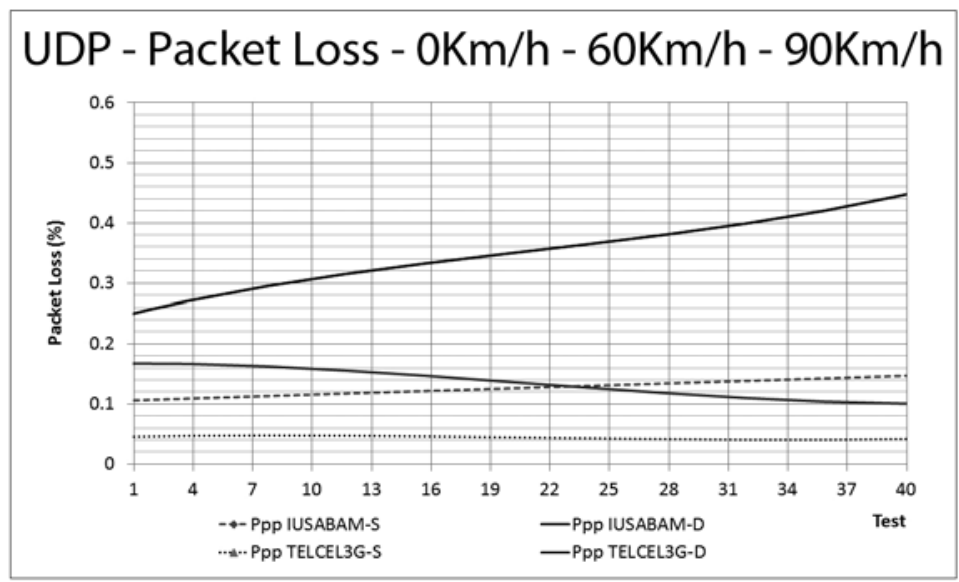

Figure 29. Average packet loss EVDO and HSDPA. 


\section{Conclusions}

We noticed that unless we used a static environment, in most of the TCP tests, the values were lower than a 50 percent of the nominal speed. Additionally, we observed that when the mobile hosts were at rest or at low speeds (60 $\mathrm{km} / \mathrm{h}$ ), the throughput was very similar or had a lineal decrease. Nevertheless, when the speed was higher $(90 \mathrm{~km} / \mathrm{h})$, the throughput had a logarithmic decrease.

For example, in the downlink, EVDO obtained 24.8 percent of the nominal value at rest, 22.8 percent at $60 \mathrm{~km} / \mathrm{h}$ and 9.27 percent at $90 \mathrm{~km} / \mathrm{h}$. On the other hand, HSDPA in the same way had more speed sensitivity than EVDO. HSDPA goes from a 32.9 percent of the nominal value at rest to a 21.5 percent at $60 \mathrm{~km} / \mathrm{h}$ and a little 8.57 percent of the nominal value at $90 \mathrm{~km} / \mathrm{h}$.

Thus we can say that the most throughput speedsensitive technology was HSDPA in the downlink. However, in the uplink, HSDPA-UMTS presented the lowest performance loss. Nevertheless, we can say that the most obstruction sensitive technology was EVDO; hence, we can ensure that most of the bad performance EVDO results (low throughput values) and disconnections were due to obstructions (vehicular traffic like cars, trucks, trailers, among others).

With UDP we obtained a little packet loss, in most of the cases (if the mobile host does not reach 90 $\mathrm{km} / \mathrm{h}$ speed) the values are lower than 1 percent. The technology with the higher packet loss value was EVDO in uplink, going from an increase of 5 percent from rest to $60 \mathrm{~km} / \mathrm{h}$ to 2.02 percent from $60 \mathrm{~km} / \mathrm{h}$ to $90 \mathrm{~km} / \mathrm{h}$.

For the jitter values, in the EVDO downlink, we obtained the better (lower) average total values at all the tests, with a 7.81 percent increase from rest to $60 \mathrm{~km} / \mathrm{h}$ and 5.58 percent from $60 \mathrm{~km} / \mathrm{h}$ to 90 $\mathrm{km} / \mathrm{h}$. Also, the RTT values were good enough to support real-time traffic (193.13 ms at EVDO and 156.2 $\mathrm{ms}$ at HSDPA).

HSDPA obtained the best throughput results at rest; thus, in this type of environment HSDPA would be better than EVDO with asymmetric data traffic like web browsing, downlink streaming, research, email, among others.

Finally, as a main conclusion from our results, we can state that we can use HSDPA and EVDO for every common application if we do not reach a higher speed than $60 \mathrm{~km} / \mathrm{h}$. But HSDPA may not perform well using applications and services with high uplink bandwidth requirements.

\section{References}

[1] Enrico Zanoio and Steve Urvik, "CDMA Network Technologies: A Decade of Advances and Challenges" Tektronix, Inc., Beaverton USA, 1998, pp. 1-9.

[2] Flavio Muratore "UMTS: Mobile Communications for the Future" Ed. John Wiley \& Sons, Italy 2001, pp. 14128.

[3] Ericsson AB, "Basic Concepts of HSPA" White Paper Uen Rev A. Ericsson, February, 2007, pp. 4-20.

[4] Telecommunications Industry Association. cdma2000® High Rate Packet Data Air Interface Specification. TIA-856-A. 2004, pp. 11-75.

[5] Qualcomm Incorporated. "EV-DO Rev. A and B: Wireless Broadband for the Masses". Qualcomm Incorporated, 2007, pp. 1-20.

[6] Third Generation Partnership Project. 3gpp TR 25.201 v5.0.0 Technical Specification Group Radio Access Network; Physical layer General description. 3GPP Release 5. 2002.

[7] Third Generation Partnership Project. 3gpp TR 25.877 v5.10 High-Speed Downlink Packet Access (HSDPA) iub/iur Protocol Aspects. 3GPP Release 5. 2002.1

[8] Third Generation Partnership Project. 3gpp TR 25.858 v5.0.0 High-speed downlink packet access, Physical layer aspects. 3GPP Release 5. 2002.

[9] Qi Bi y Vitebsky, S. "Performance analysis of 3G-1X EVDO high data rate system". Lucent Technol. Inc., Wireless Communications and Networking Conference (WCNC2002), IEEE, , Vol. 1, 2002, pp. 389-395.

[10] Harteneck, M., Boloorian, M., Georgoulis, S. y Tanner, R. "Throughput measurements of HSDPA 14 Mbit/s terminal". Cambridge Technology Centre, UbiNetics Ltd., Electronics Letters Issue Melbourn, United Kingdom, Vol. 41, No. 7, 2005, pp. 425-427. 
[11] G.D.G. Jaime, R.M.M. Leão, E. de Souza e Silva y J. Roberto B. de Marca. "The Effect of Mobility on the User-Level Fairness of a $3 G$ Wireless Technology (EV-

DO)". Wireless Communications and Networking Conference, 2008. WCNC 2008, IEEE, Las Vegas, USA, 2008 , pp. 3303 - 3308.

[12] Iusacell [Online] Available at:

http://www.iusacell.com.mx/New_Site.

[13] Telcel es la Red [Online] Available at: http://www.telcel.com/portal/home.do

[14] MyConnection Server network assessment testing, network route performance, VolP quality testing [Online] Available at: http://www.myconnectionserver.com.

[15] MyConnection PC connection test, bandwidth speed test, VolP quality testing [Online] Available at: http://www.myconnectionpc.com. 